\title{
ESPAÇO ESCOLAR E HISTÓRIA DAS INSTITUIÇÕES ESCOLARES
}

\section{School Space and School Institutions History}

\author{
Flávia Obino Corrêa Werle \\ Lenir Marina Trindade de Sá Britto ${ }^{2}$ \\ Cinthia Merlo Colau ${ }^{3}$
}

\section{Resumo}

O texto constitui-se em contribuição teórica para a discussão da história das instituições escolares, seus prédios e espaços. Discute narrativas que constituem a história das instituições escolares em seu conteúdo de interpretações e de releituras do espaço físico escolar. Analisa a apropriação dos espaços escolares pelos atores e a identidade institucional. A discussão é feita com base em Michel de Certeau.

Palavras-chave: História da educação; Espaço escolar; Instituições escolares.

\section{Abstract}

The text constitutes itself as a theoretical contribution to the discussion about the school institutions history, its buildings and spaces. It discusses narratives that constitute school institutions history in its content of interpretations and of rereadings of the school physical space. It analises the appropriation of the school spaces by the actors and the institutional identity. The discussion is made in the basis of Michel de Certeau.

Keywords: Education history; School space; School institutions.

\footnotetext{
1 Drª Em Educação, Professora do Programa de Pós-Graduação em Educação da Universidade do Vale do Rio dos Sinos - UNISINOS, e-mail: flaviaw@unisinos.br

2 Graduanda de Pedagogia, UNISINOS, bolsista PIBIC. e-mail: moonteacher@hotmail.com

3 Graduanda de Pedagogia, UNISINOS, bolsista CNPq. e-mail: cinthia@bage.unisinos.br
} 


\section{Introdução}

A história das instituições escolares (HIE) pode ser considerada uma abordagem que fomenta, no campo da história da educação, uma renovação metodológica e teórica ao instigar trabalhos que discutem as relações dialéticas entre o universal e o particular. Pela análise dos "casos" singulares, provoca abordagens que focalizem os micromovimentos e propostas dos estabelecimentos de ensino em diálogo com as políticas educacionais e macroprojetos de renovação pedagógica. A base material é um dos elementos necessariamente considerados para compor a cena do relato da história institucional. O presente texto constitui-se num contributo teórico para a discussão da História das Instituições Escolares em sua referência a prédios e espaços ocupados pelas escolas, analisando as possibilidades de apropriação dos espaços escolares pelos atores e as relações entre as representações dos espaços e a identidade institucional. A discussão é feita com base em Michel de Certeau (1996), refletindo acerca das categorias de espaço, região, percurso, lugar e mapas como elementos para a inteligibilidade e construção da História das Instituições Escolares. São apresentados alguns depoimentos colhidos em entrevistas com ex-alunas de Escolas Complementares e com ex-alunos de Escolas Normais Rurais do Rio Grande do Sul. ${ }^{4}$

\section{História das instituições escolares na história da educação brasileira}

A História das instituições educativas tem tomado fôlego no contexto dos estudos de história da educação no Brasil, inserindo-se num processo de renovação no campo da história da educação e constituindo-se como um novo campo temático da historiografia da educação brasileira (GATTI JUNIOR, 2002, p. 19). Com base em Magalhães, Gatti afirma que a história das instituições educativas investiga o que se passa no interior da escola pela "apreensão daqueles elementos que conferem identidade à instituição educacional, ou seja, daquilo que lhe confere um sentido único no cenário social do qual fez ou ainda faz parte, mesmo que ela tenha se transformado no decorrer dos tempos." (GATTI JUNIOR, 2002, p. 20). Assim, envolve descrições sobre o ciclo de vida das instituições - criação, desenvolvimento, crises e extensão -, elementos da arquitetura, perfil de seus agentes, envolvendo corpo docente,

\footnotetext{
4 As entrevistas foram realizadas no contexto dos projetos de pesquisa "Escola Complementar: Práticas e Instituições" - 2001/2003, apoio Fapergs e CNPq e "História das Instituições Escolares: escolas de formação de professores" - 2004/2006, apoio CNPq.
} 
funcionários, apoio, perfil de alunos, projetos e propostas pedagógicas, dentre outras.

Para Buffa (2002), a pesquisa acerca das instituições escolares é uma forma de estudar a história e a filosofia da educação brasileira, na medida em que as instituições que compõem os sistemas escolares estão impregnadas pelos valores de cada época. A pesquisa em história das instituições escolares tem como vantagem a possibilidade de "superar a dicotomia entre o particular e o universal, o específico e o geral, o concreto e o conceito, a história e a filosofia." (BUFFA, 2002, p. 26). A autora destaca que fragmentos de matizes filosóficas variadas, e por vezes opostas, perpassam as motivações de criação, mudança, desenvolvimento das instituições, movimentos de articulação e de fragmentação repercutem nas interações entre alunos e professores, articulações curriculares são desdobradas pela maior ou menor autonomia e criatividade dos componentes da escola. Há princípios teórico-metodológicos que orientam o trabalho do pesquisador envolvido com história das instituições educativas contemplando: (a) a compreensão do alto nível de complexidade entre as relações trabalho e educação; (b) o entendimento de que o particular é uma expressão do desenvolvimento geral - visões gerais e descrições do singular; (c) a consideração da história das instituições educativas como uma ação de interpretação, não apenas descritiva. Buffa, inspirada na obra de André Petitat, propõe categorias:

Investigar o processo de criação e de instalação da escola, a caracterização e a utilização do espaço físico (elementos arquitetônicos do prédio, sua implantação no terreno, seu entrono e acabamento), o espaço do poder (diretoria, secretaria, sala dos professores), a organização e o uso do tempo, a seleção dos conteúdos escolares, a origem social da clientela escolar e seu destino provável, os professores, a legislação, as normas e a administração da escola. Estas categorias permitem traçar um retrato da escola com seus atores, aspectos de sua organização, seu cotidiano, seus rituais, sua cultura e seu significado para aquela sociedade. (BUFFA, 2002, p. 27).

As fontes indicadas pela autora são variadas: jornais da época, legislação, literatura pertinente, entrevistas, fotografias e documentação da instituição escolar. Em seu artigo publicado no livro Novos temas em história da educação brasileira, Buffa faz um estudo sobre os prédios escolares de três escolas de uma cidade do estado de São Paulo: o da Escola Normal Secundária, indicando pisos, dependências, acabamentos e soluções construtivas, o da Escola Profissional, inicialmente construído para o funcionamento de uma casa de saúde, e o da Escola de Engenharia de São Carlos/USP, o qual funcionou em vários locais (GATTI JUNIOR, 2002). 
Outros autores, como Magalhães (1999), Felgueiras (1998) destacam a importância da base material. Felgueiras considera o local em que a vida institucional ocorreu, os materiais, artefatos, móveis e utensílios, os espaços e seus objetos, enfim, como "sítio histórico" cuja consideração é indispensável para que se possa fazer interpretações, leituras interpretativas, relatos sobre a história institucional. Portanto, vários autores incluem como elemento indispensável na composição da história de instituições escolares a consideração do espaço físico ou base material da instituição.

\section{Relatos de história das instituições escolares: compondo a cena}

A História das Instituições Escolares configura-se em relatos escritos, os quais devem construir um teatro, um campo para ações efetivas. Neste trabalho, utiliza-se narrativa, relato, exposição como sinônimos, sempre referidos a texto escrito com intencionalidade, a qual diretamente o situa, como parte do que se entende por História das Instituições Escolares. Assume-se, também, no que se refere à forma escrita, a formulação dada por Koch e Travaglia (2000, p. 8), que explicitam o texto:

Como uma unidade lingüística concreta (perceptível pela visão ou audição), que é tomada pelos usuários da língua (falante, escritor/ouvinte, leitor), em uma situação de interação comunicativa específica, como uma unidade de sentido e como preenchendo uma função comunicativa reconhecível, reconhecida, independentemente de sua extensão.

É relevante, portanto, explicitar na forma escrita a intencionalidade, nesse caso a de inserção no campo da História das Instituições Escolares. Como texto escrito, tem uma autoria e propósito, que conformam, com especificidade, a direção comunicativa - do autor para o leitor. Certeau reflete acerca da escrita como "derradeiro momento" (CERTEAU, 1996, p. 298) corroído pela conflitualidade entre a busca e a perda de sentido e da repercussão inusitada do texto escrito no leitor.

Prática da perda da palavra, a escritura só tem sentido fora de si mesma, num lugar outro, o do leitor, que produz como a sua própria necessidade indo ela mesma para esta presença que não poderia ganhar. Vai em direção a uma palavra que não lhe será jamais dada e que, por isso mesmo, constrói o movimento de ser indefinidamente ligada a uma resposta solta, absoluta, a do outro. (CERTEAU, 1996, p. 299). 
Mesmo sob a forma descritiva, o relato é criativo: "toda a descrição é mais que uma fixação", é "um ato culturalmente criador." (LOTMAN apud CERTEAU, 1996, p. 209). A descrição tem força performativa, de ordenação, disposição, "ela realiza o que diz". No âmbito da História das Instituições Escolares, o relato escrito descritivo tem a função de estabelecer uma superfície, conformar, circunscrever o contexto. A História das Instituições Escolares é uma composição de relatos, narrativas, portadoras desta força performativa.

Uma das características importantes dos relatos que constroem a História das Instituições Escolares é que ele "tem inicialmente uma função de autorização, ou, mais exatamente de fundação" [...] abrindo um "teatro de legitimidade a ações efetivas." É o relato que estabelece a disposição dos dados, possibilita descortinar um contexto, um ambiente, atuando como um "mapeamento dinâmico do espaço" (CERTEAU, 1996, p. 209-210).

Descrever a base material é um elemento importante da composição dessa cena fundacional do teatro em que se desenrola a História Institucional, dimensionando o espaço em que os diversos atores, as múltiplas políticas, os poderes institucionalizados elaboram seus percursos.

Um relato, ao configurar a cena, opera, pelo menos, em dois níveis: numa dimensão temporal e numa dimensão temática, estabelecendo um vetor de orientação.

\section{Dimensão temporal}

Necessariamente, a HIE maneja com a dimensão temporal. O pesquisador de HIE vê-se à frente de indagações acerca do período de tempo abrangido no relato. Trabalhar com HIE não é permanecer na presencialidade, no hoje da instituição, mas descrever, compor narrativas de seus diferentes momentos de existência.

Todos os fatos educativos são históricos. Configurações específicas os precedem, tramas de encaminhamentos são tecidas ao longo do tempo. Isso significa que uma historicidade reflexiva acompanha todos os estudos relacionados à educação ${ }^{5}$ mesmo que sejam orientados preferencialmente para

\footnotetext{
5 Eventos acadêmicos temáticos sobre História da Educação, realizados no Brasil, têm seguidamente acolhido estudos de nítida presencialidade, o que demonstra quanto ainda, como academia, temos que problematizar a dimensão temporal dos estudos que produzimos referidos ao campo da História da Educação. NUNES, Clarice. História da educação Brasileira: novas abordagens de velhos objetos. Teoria \& Educação, Porto Alegre, n. 6, p. 151-182, 1992. - apóia a nossa constatação de que trabalhos aceitos como históricos analisam de fato acontecimentos do presente, o que possivelmente decorra da atual compreensão do relativismo da ciência histórica e da concepção histórica contemporânea que questiona a visão de que história seja a ciência do passado.
}

Diálogo Educ., Curitiba, v. 7, n. 22, p. 147-163, set./dez. 2007 
o presente e o futuro. A HIE, entretanto, é orientada para um desvelamento do passado das instituições escolares. Justino Magalhães, em seminário ${ }^{6}$ sobre História das Instituições Educativas (2001), indica um distanciamento de 30 anos como característica de constituição de relatos de HIE.

Para armar o relato das características da base material que vão constituir, em parte, o teatro no qual ocorrem percursos de diferentes propostas, muito contribuem documentos, plantas arquitetônicas, fotos e imagens. Grande parte das vezes, as imagens aparecem como fragmentos da cena escolar. A fotografia de uma escada, um pátio, uma sala são migalhas de uma cena, estilhaços de um espaço escolar, os quais, se não contextualizados, pouco poderão auxiliar na configuração da cena.

Do distanciamento temporal decorrem implicações para o relato especialmente no foco de suas características materiais, espaços, equipamentos, mobiliário, decoração, instrumentos e materiais pedagógicos. Mesmo em instituições que ainda estejam em funcionamento, se não houver quem ou o que explique as articulações espaciais, se não houver um conjunto de imagens que consigam explicitar minimamente as formas de funcionamento dos espaços, dificilmente poderemos armar relatos suficientemente claros e articulados. Imagens, fotografias e plantas arquitetônicas isoladas com freqüência poderão constituir apenas fração a que não se consegue dar inteligibilidade com suficiente articulação. As reformas, ampliações, intervenções no sentido de modernizar e prover mais segurança ao prédio são fatores que implicam na configuração da cena e na compreensão acerca da forma como a instituição se desenvolveu e respondeu a demandas por expansão ou por especialização de serviços.

\section{Base material como dimensão temática ou vetor de orientação do relato}

Adotamos a posição de Chapoulie e Briand apud Desaulniers (1992, p. 98-99), que afirmam:

\footnotetext{
6 Professor Justino Magalhães ministrou, no período de 4 a 14 de dezembro de 2001, dois seminários, cada um de 15 h/a, no Programa de Pós-Graduação em Educação da UNISINOS, São Leopoldo, Rio Grande do Sul. Participou de um encontro de estudos promovido pela ASPHE - Associação Sul-Rio-Grandense de Pesquisadores em História da Educação -, bem como de uma Oficina sobre Preservação da História Institucional e documentos escolares. Estas atividades acadêmicas foram apoiadas pelo CNPq (Processo número 45.3384/01-3 - APV) e FAPERGS e organizadas por Werle e Redin.
} 
A instituição se constitui de um conjunto de relações sociais, as quais se instauram a partir de uma base material. Sendo assim, a análise do funcionamento da instituição escolar, através dos seus aspectos materiais e administrativos, como também das práticas, dos interesses e das categorias de interpretação dos diversos grupos de agentes, é fundamental para explicar a evolução da escolarização.

Construir um relato acerca da História Institucional implica em tomar um vetor como forma de orientar a argumentação sem se esquecer da diversidade que compõe a HIE. Neste nível, cabem algumas indagações. Qual a abordagem? O prédio visto pelos alunos? Onde encontrar a representação das apropriações dos alunos sobre o prédio escolar? Em produções escritas, como impressos estudantis, revistas e boletins? Como articulá-la com os movimentos de outros segmentos da instituição, com dimensões pedagógicas e políticas? Como a história das equipes diretivas repercute na estrutura física da escola? Há articulações entre a base material e as configurações do fazer docente, dos projetos pedagógicos da instituição, dos regimentos, planos e normatizações?

Os relatos configuram um lugar, uma cena, o espaço do teatro em cujos limites são tecidos percursos que decorrem do vetor estruturador da argumentação.

M. Certeau diz que as estruturas narrativas são sintaxes espaciais, são práticas de espaço. "Os relatos poderiam igualmente ter esse belo nome [metáfora]: todo dia, eles atravessam e organizam lugares; eles os selecionam e os reúnem num só conjunto; deles fazem frases e itinerários. São percursos de espaços." (CERTEAU, 1996, p. 199).

Não apenas a codificação da temporalidade está registrada nos relatos de História das Instituições Escolares, mas os indicativos de elementos da cena - alunos, prédio, normas de gestão - registrando descrições de atores, indicando mobilidade entre espaços, deveres e formas de conhecimento. Assim, relatos da História das Instituições Educativas "produzem geografias de ações" e organizam caminhos (CERTEAU, 1996, p. 200).

São exemplificativas destas características as lembranças relatadas por complementaristas entrevistadas nas quais as experiências são referidas às características dos espaços e das normas de uso destes espaços impostas pela instituição ou a comportamentos de infração da norma de uso deles. 
E uma noite foi combinado de noite bater na tampa do pinico. A minha cela era bem pertinho da cela da Irmã [...], era esquina já, porque eu era das impossíveis, mas eu não fiz nada e aí elas combinaram, lá embaixo, que todo o mundo faria. A Teresinha ia dizer não sei o quê, alto, e todo o mundo ia bater com a tampa do pinico, daí a freira ia ficar bem doida e não ia saber quem é que era. Não teve dúvida. Eu disse: hoje eu não vou fazer nada. Começou a bateção de pinico [...] e a Irmã [...] veio para a minha cela.

Eu tinha uma gabardine que pendurava lá embaixo, naquele saguão grande lá. Hoje acho que nem sei o que é aquilo. A gente guardava as roupas embaixo, no último piso. [Hoje estes espaços são ocupados com sala de artes e sala de game]. Lá era aberto e havia números [nos cabides de cada aluna]. Meu número era cento e setenta e oito. Coloquei uma gabardine velha e dentro da gabardine tinha doce de leite e lingüiça. E daí, conforme eu convidava [uma ou outra colega sussurrando ao ouvido] - Hoje tem gabardine! (Entrevistas com ex-complementaristas).

As experiências de transgressão relatadas intercalam referências a lugares, constituindo espaços de proximidade (a aluna considerada mais indisciplinada tem sua cama situada próxima ao lugar de descanso da Irmã que cuidava do dormitório; o local de guardar o abrigo de sair para a rua situava-se afastado dos locais de convívio cotidiano; com o tempo os espaços têm seus usos alterados, introduzindo um fator de desconhecimento/ estranhamento naqueles que neles viveram há mais tempo).

As formas de estar e de apropriar-se dos espaços da Instituição Escolar -identificáveis nas manifestações dos diferentes segmentos perceptíveis em relatos orais e escritos e em outros tipos de representações, imagens, desenhos, sinalizam três direções. Assinalam (a) um processo de apropriação do sistema topográfico do estabelecimento de ensino, (b) constituem a realização espacial do lugar e (c) contribuem para a diferenciação de poderes e de relações que ocorrem na instituição.

Caminhar pelos espaços da escola propicia a apropriação de sua topografia. Espaços interditos, espaços exclusivos são mapeados diferentemente pelos componentes da instituição escolar. A clausura em escolas de congregações religiosas femininas, a capela, os laboratórios, as salas das professoras (só para mulheres) e a sala dos professores (só para os homens), os dormitórios que distribuíam alunas de acordo com as idades muito amplos e com camas lado a lado para as menores -, e as celas individuais para as maiores. A dimensão do prédio e a relação dos aposentos bem como a faixa etária e funções dos seus ocupantes configuram percepções e apropriações que ficam marcadas na memória dos que passaram pela instituição escolar. 
Há "uma ordem espacial que organiza um conjunto de possibilidades [...] e proibições" - locais de circulação, locais de estar nos recreios, locais em que se estuda tal ou qual matéria (CERTEAU, 1996, p. 177). Se a base material traz em si uma previsão de uso, é nela que se constroem inéditas relações de apropriação, rompendo, muitas vezes, com as propostas para as quais foram concebidas. Assim se configuram os relatos que referem o estudo, nas vésperas de provas embaixo da cama onde velas iluminavam a leitura escondida, ou os que registram a hilariante descida sentada no corrimão da escada.

Eu era impossível. Era uma das primeiras alunas, mas eu era impossível. Isso de descer pelo corrimão, de fazer arte, eu estava sempre junto. E um dia a Irmã [...] me pegou descendo no corrimão e ela fazia com o dedo assim: Tu no final do ano vais voltar em cima da mala. Na mala quer dizer expulsa. (Entrevista com ex-aluna de Escola Complementar).

Ao longo do tempo, tais relações com os espaços vão sendo reinventadas não apenas no plano da transgressão individual ou de grupo, mas pela própria instituição, pelos novos projetos institucionais em decorrência das novas exigências de espaços e de reorganização administrativa. Assim um imenso pátio ao ar livre em determinado período da história institucional passa a ser limitado pelo pavilhão de educação física construído nos mais modernos requisitos arquitetônicos que fala da atualização da proposta educativa da escola e do esforço de diversificação de atividades, mas que elimina a vista que se descortinava da escola para a cidade.

Lembrar a poética com que Certeau refere a ação de construção da espacialidade, tanto a que reitera a lógica organizadora dos espaços projetados como a transgressora que inventa novas formas/espaços e inusitadas trajetórias de uso, aprofunda a reflexão acerca dos movimentos de apropriação da base material e da história institucional. "Os jogos de passos moldam espaços. Tecem lugares. Sob esse ponto de vista, as motricidades dos pedestres [...] espacializam" (CERTEAU, 1996, p. 176).

O caminhar, correr, andar pelos espaços faz com que os espaços sejam preenchidos pela vida e apareçam, embora o caminhar como uma apropriação também desloque significados em tais espaços pela invenção de outros usos. "[...] as idas e vindas, as variações ou as improvisações da caminhada privilegiam, mudam ou deixam de lado elementos espaciais." (CERTEAU, 1996, p. 178).

A apropriação possibilita ultrapassar os limites que as determinações de espaços e objetos possam fixar para seu uso. Assim o caminhar pelos espaços escolares transforma cada significante espacial. De um lado, ele torna efetiva a ordem construída (vai somente por aqui, mas não por lá; desça a escada pelo seu lado direito e suba a escada também pelo seu lado direito; 
corrimão serve para apoiar a mão de quem está subindo ou descendo a escada), de outro, instaura inimagináveis possíveis usos e interditos (por exemplo, criando atalhos ou desvios, tornando espaços do pátio previstos como locais para a folga, para o pega-pega no recreio, em lugares de fuga da disciplina escolar e de vadiação; e o corrimão como escorregador). Desta forma, podem ser interpretados os usos que rompem e negam os caminhos considerados lícitos ou obrigatórios: não seguir na fila, ao contrário, marchar correndo, ou de esguelha, encostando-se nas paredes; riscar nas paredes; fugir pela janela. Em decorrência da base material, os diferentes atores da instituição criam modos de apropriação, seguindo ou infringindo regras de uso, contribuindo para estabelecer outras relações com o espaço escolar. Portanto, os ocupantes dos prédios escolares produzem deslocamentos pelo uso que fazem deles ou, pelo não uso, condenam-nos ao desaparecimento e à inércia.

\section{Base material: distinções entre espaço e lugar e entre mapas e percursos}

Uma narrativa referente à HIE precisa definir lugares como também articular interações, conflitos, aspectos estes que constituem tais lugares em espaços de relações.

Um lugar é a ordem [...] segundo a qual se distribuem elementos nas relações de coexistência. Aí se acha portanto excluída a possibilidade, para duas coisas, de ocuparem o mesmo lugar. Aí impera a lei do 'próprio': os elementos considerados se acham uns ao lado dos outros, cada um situado num lugar 'próprio' e distinto que define. Um lugar é portanto uma configuração instantânea de posições. Implica uma indicação de estabilidade. (CERTEAU, 1996, p. 201).

Sendo configuração de posições, o lugar é inerte, estável e, ao contrário, o espaço é vivo de interações e poderes.

Existe espaço sempre que se tomam em conta vetores de direção, quantidades de velocidade e a variável tempo. O espaço é um cruzamento de móveis. É de certo modo animado pelo conjunto dos movimentos que aí se desdobram. Espaço é o efeito produzido pelas operações que o orientam, o circunstanciam, o temporalizam e o levam a funcionar em unidade polivalente de programas conflituais ou de proximidades contratuais. (CERTEAU, 1996, p. 202).

A diferenciação entre lugar - frio, estático, congelado -, e espaço é que este constitui "um lugar praticado" (CERTEAU, 1996, p. 202). 
O grande desafio de fazer História das Instituições Escolares é construir espaços e não apenas lugares. Espaço compreendido como um cruzamento, como movimento, contraposto a lugar como ordem, relação entre elementos posicionados entre si, preestabelecidos. Assim, um lugar admite muitos relatos de espaços vistos de forma diferente em decorrência dos atores e acontecimentos em decorrência dos projetos e das temporalidades. Assim, "existem tantos espaços quantas experiências espaciais distintas", pois os espaços estão vinculados a ações de sujeitos históricos (MERLEAU-PONTY apud CERTEAU, 1996, p. 202). Cabe aos relatos operarem esta transformação de lugares em múltiplos espaços pela articulação entre diferentes bases documentais, imagéticas e que explicitam apropriações diferenciadas.

M. Certeau distingue também mapas de percursos. Relatos de tipo mapa exprimem o que se vê, demarcam fronteiras, indicam certa ordem dos lugares, delineando um quadro. Esta distinção é importante para a HIE que intenta apreender no relato a dinâmica social e seu desenrolar ao longo do tempo.

A complexidade da constituição dos relatos de HIE decorre da necessidade de intercalar os percursos e os mapas, os lugares e os espaços, pois eles se complementam e condicionam.

A cadeia das operações espacializantes parece toda pontilhada de referências ao que produz (uma representação de lugares) ou ao que implica (uma ordem local). Tem-se assim a estrutura do relato de viagem: histórias de caminhadas [..] são marcadas pela 'citação' dos lugares que daí resultam ou que as autorizam. (CERTEAU, 1996, p. 205).

Nas falas das entrevistadas e entrevistados de nossas pesquisas, parece predominar o percurso. O mapa, o lugar ficam subsumidos, como que invisíveis na fala, não pronunciado nas entrevistas que destacam o percurso, para a interação e experiência subjetiva. Ou seja, "[...] os relatos cotidianos contam aquilo que, apesar de tudo, se pode aí fabricar e fazer. São feituras de espaço." (CERTEAU, 1996, p. 207). Os relatos que constituem a HIE são, portanto, uma forma de expressar operações sobre os lugares. Os lugares cercam os projetos, mas por sua vez, os projetos exigem lugares diferenciados. A formação do professor rural, por exemplo, é explicada com a referência a lugares - visitas a escolas -, a disciplina é evidenciada pela referência a lugares que, conforme a situação, tornam-se espaços de disciplina e ordem ou espaços coletivos de jogos e esporte. 
Eu me lembro, foram algumas visitas a escolas rurais, eles levavam para a gente conhecer o que era uma escola rural, conversar com professor. Para ter uma idéia mais aproximada da atividade de profissional. Bom, então veja bem, a disciplina era essa, ou seja, para ter uma idéia do que era a disciplina os horários eram rígidos. Horário de levantar e de deitar, os horários intermediários que eram destinados a aulas e ao lazer também, tínhamos jogos, nós jogávamos muito. (Entrevista com ex-aluno de Escola Normal Rural).

A complexidade dos relatos sobre instituições escolares pode ser também discutida com o suporte do conceito de região (MILLER; JOHNSONLAIRD apud CERTEAU, 1996, p. 212). Região é "um encontro entre programas de ação. A 'região' vem a ser, portanto o espaço criado por uma interação. Daí segue que num mesmo lugar há tantas regiões quantas interações ou encontros entre programas." (CERTEAU, 1996, p. 212).

Programas de ação em HIE podem ser entendidos como interesses de diferentes segmentos, embates entre grupos rivais ou em disputa acerca de visões de mundo diferentes. Região é, pois, uma interação com complexo conteúdo temático. A própria instituição escolar em estudo pode ser considerada uma grande região na qual em tempos e espaços diferentes se constituíram diferentes projetos. Ou no interior de uma instituição escolar muitas regiões são criadas.

Uma exemplificação deste conceito de região é a referência a cursos com status diferenciados, convivendo em um mesmo prédio. No relato de um ex-normalista, fica evidente a disputa e o tratamento diferenciado entre ginasianos e normalistas. Ou seja, pertencer a este ou aquele curso atribuía diferenciações entre os alunos e entre os espaços destinados a uns e a outros, ainda que dentro de uma mesma escola.

Também tinha um internato só para pessoas do ginásio. E o interessante é que os dormitórios eram separados, por que os ginasianos que pagavam particularmente, eles gozavam, assim, de uma espécie de diferenciação, eles não trabalhavam, só faziam serviços assim [leves]. Para tu ter uma idéia eu lavava [banheiros], e até gostava muito de fazer, o trabalho que eu mais gostava, caprichado. Isso os ginasianos não faziam. Os ginasianos não serviam nos refeitórios. Os alunos normalistas, na hora do almoço, da janta, do café da tarde levavam, serviam. (Entrevista com ex-complementarista).

Região pode também ser considerada uma referência a um lugar a qual não indica apenas lugares, mas a vida que ali ocorria. Por exemplo, um entrevistado que freqüentara a Escola Normal Rural de Guaporé, ao nomear o bairro em que vivia com a família, antes de ir como aluno interno para a 
escola, referindo o bairro Cidade Baixa em Porto Alegre, disse "aquilo ali era meu reino", nitidamente referindo-se a uma região, um espaço criado por interações felizes para o depoente.

Certeau fala em contradição dinâmica entre delimitação e mobilidade, o que certamente ocorre no esforço de construção de relatos acerca da História das Instituições Escolares.

De um lado, o relato não se cansa de colocar fronteiras. Multiplica-as, mas em termos de interações entre personagens - coisas, animais, seres humanos: os actantes repartem lugares entre si ao mesmo tempo em que predicados (bom, astucioso, ambicioso, simplório, etc.) e movimentos (adiantarse, subtrair-se, exilar-se, voltar-se, etc.). Os limites são traçados pelos pontos de encontro entre as apropriações progressivas (a aquisição de predicados no curso do relato) e os deslocamentos sucessivos (movimentos internos ou externos) dos actantes. Devem-se estes limites a uma distribuição dinâmica dos bens e das funções possíveis, para constituir, sempre mais complexificada, uma rede de diferenciações, uma combinatória de espaços. Resultam de um trabalho da distinção a partir de encontros (CERTEAU, 1996, p. 213).

Um dos depoimentos colhidos junto à ex-alunos de escolas normais rurais pode exemplificar esta dinâmica entre delimitação e mobilidade referida por Certeau.

Lá em Guaporé, por exemplo, eu comecei a criação do bicho-da-seda, foi minha iniciativa. Então por todo o período, todo o período que eu estive lá, durante os dois anos eu mantinha os bichos-da-seda, por livre e espontânea vontade. Eu sugeri que não sairia muito da vida rural, então eu, essa do bichoda-seda fui eu que, eu e alguns poucos alunos, amigos, colegas, amigos que eu convidava. A gente, saia da escola para buscar, folhas de amora. Era uma forma, inclusive, de fuga daquela reclusão permanente sabe, por que aquilo era uma disciplina rígida, por que tinha dias de saída, horários de saída e volta. Então para mim sair um pouco mais, eu arrumei essa forma de buscar, eles me permitiam que eu fosse lá buscar as folhas. (Entrevista com ex-aluno de Escola Normal Rural).

O espaço do internato narrado por este entrevistado, delimitador, invadido de disciplina e de ordenamentos provocava estratégias de fuga. Sair para buscar folhas de amora se constituía não numa tarefa de formação planejada pela escola. Embora não se afastasse muito da proposta formativa do estabelecimento de ensino, neste caso era uma forma de burla da cerrada disciplina e confinamento no prédio escolar. A criação de bichosda-seda exigia um certo tipo de vegetação inexistente no delimitado lugar escolar. 
Portanto, se lugar e mapa são categorias que sinalizam para elementos mais estáticos na cena, então, região, percurso e espaço indicam relações dinâmicas, integrações. Pode-se descrever uma instituição escolar na forma de um mapa e de um lugar sem chegar a registrar os espaços, regiões e percursos que ela contém. Registros de espaços, regiões, percursos são muito mais exigentes, pois focalizam o local, o micro em suas diferentes dinâmicas interacionais.

Há narrações que organizam espaços e demarcações que instauram deslocamentos, movimentos do espaço.

O relato de espaço é em seu grau mínimo uma língua falada, isto é, um sistema lingüístico distributivo de lugares sendo ao mesmo tempo articulado por uma 'focalização enunciadora', por um ato que o pratica. [...] Basta aqui, antes de ir buscar as suas indicações na organização da memória, lembrar que com essa enunciação focalizante o espaço surge de novo como lugar praticado. (CERTEAU, 1996, p. 217).

Certeau aqui nos lembra que sempre há um autor, com idade, determinadas experiências, pertencente a um grupo social, com um ponto de vista. Este autor refere aos lugares, mas de um ponto de vista fala de espaços, relações, regiões, percursos. Os relatos de espaço não são o lugar, mas pontos de vista acerca dele, são o lugar praticado.

\section{Base material, relações com a cidade, dúvidas e medos}

A apropriação dos elementos que constituem a base material da instituição escolar não é um processo circunscrito à comunidade interna, mas ampliado para a cidade. A materialidade da escola tem significado para a identidade institucional e para a sociedade, para os moradores das cercanias do prédio escolar. Implica na vida dos moradores da cidade, mesmo que estes não tenham estudado, trabalhado ou enviado seus filhos e netos para aquele estabelecimento de ensino. À cidade como um todo pertence a escola e, portanto, a preservação da memória de instituições escolares está afeta ao ambiente no qual a escola se insere, às ruas e demais prédios, à vizinhança, bairro.

Nessa dimensão, as interações na base material da instituição escolar podem significar traição na perspectiva de intervenção/sonegação da memória social.

Fernández (1998), estudando o impacto das mudanças causadas pelos projetos de inovação educativas em instituições escolares, refere medos e 
dúvidas que eclodem. Umas visualizando a mudança como traição, destruição, outras considerando a mudança como uma mentira, ficção, engano, outras ainda considerando-a um erro, pois a situação era melhor antes e as inovações são consideradas como desordenadas (a ordem ocorria na situação anterior), e caóticas.

No plano individual da memória dos que viveram há mais tempo em uma instituição escolar, elementos do lugar e do mapa são inerentes ao espaço; alterá-los implica em intervir na ordem e na "verdade" das lembranças pessoais. $\mathrm{Na}$ perspectiva da revisitação, pela memória, de experiências vividas na instituição escolar, as alterações impostas ao prédio, decorrentes de ampliação, reforma, modernização do projeto são vistas como traição ao espaço conhecido, o qual, ao apresentar um lugar com características diferentes, um novo mapa demarcando novos usos, como que impõe um elemento estranho, um impasse às lembranças, corrompendo-as.

Traição a uma possibilidade de rever os espaços tais quais se distribuíam e que hoje passam a existir apenas com as molduras da memória. Traição considerada pelos que ali viveram e que, retornando àqueles ambientes, não encontram mais os mesmos lugares. Os mapas que a memória deles carrega não coincidem com os lugares disponíveis hoje na instituição escolar. Os novos mapas que constituem novos lugares decorrem de intervenções, grande parte das vezes motivada pela ânsia de modernismo, competitividade, expansão por que passam muitas escolas hoje.

\section{Elementos conclusivos}

A História das Instituições Escolares desponta como estratégia de fazer história da educação e, embora enfocando a singularidade do "caso", oferece conhecimentos acerca das relações sociais mais amplas, dos sistemas educativos, dos impactos das políticas educativas no âmbito institucional. A base material fornece importante compreensão das relações internas da escola, suas funções, clientela, prestígio, inserção no plano da cidade. Articulada aos componentes da base de gestão, aspectos interacionais, apropriações dos diferentes atores e públicos atendidos, a base material contribui para compor o relato interpretativo, ou seja, a história institucional. Assim se afirma, pois a história das instituições escolares é um esforço de bricolagem de fragmentos de histórias anteriores, de múltiplas representações e apropriações, de muitos narradores, configurando uma parte ínfima “... da narração oral que não cessa trabalho interminável, de compor espaços, verificar, confrontar e deslocar suas fronteiras" (CERTEAU, 1996, p. 208). 
Entretanto, um risco deve ser evitado, referido por Certeau como miniaturização. Tal perigo pode estar presente nos relatos produzidos no campo da História das Instituições Educativas quando estes perdem a característica de teatro, de espaço de força e configuração da cena. Entende-se por miniaturização a conseqüência da exacerbação do pressuposto de que existem histórias - no plural - e não uma história institucional. Miniaturização é permanecer apenas no relato do mapa, do lugar sem incrementá-lo com regiões, enriquecê-lo com espaços e percursos. Miniaturização também é tratar percursos de espaços, regiões de interação e conflitos como se estivessem ali presentes e percebidos por todos nós. Miniaturização é tratar como sendo História das Instituições Escolares os micros relatos de partes - aproximados de descrições -, fragmentos mínimos da história institucional, o que acarreta limitação e redução na compreensão da história institucional. Não mais a instituição como objeto; prevalecem outros focos temáticos. Miniaturização pode ser o resultado da multiplicação de histórias institucionais, sejam elas produzidas pela própria instituição, ou por estrangeiros ${ }^{7}$ A miniaturização pode também ocorrer quando os relatos considerarem períodos da história dessas mesmas instituições, os quais, analisados não mais como parcela, mas como unidade de HIE. A miniaturização limita problematicamente a História Institucional produzindo "cacos" pela produção de variados microrrelatos.

\section{Referências}

BUFFA, Ester. História e filosofia das instituições escolares. In: ARAÚJO, José Carlos Souza; GATTI JUNIOR, Décio (Org.). Novos temas em historia da educação brasileira: instituições escolares e educação na imprensa. Campinas/ SP: Autores Associados; Uberlândia: EDUFU, 2002. p. 25-38.

CERTEAU, Michel de. A invenção do cotidiano. Petrópolis: Vozes, 1996.

DESAULNIERS, Julieta Ramos. Instituição e evolução da escolarização. Teoria \& Educação, Porto Alegre, n. 6, p. 97-104, 1992.

FELGUEIRAS, Margarida Maria Louro. Para um museu vivo da escola primária: trajectória de uma investigação. In: MAGALHÃES, Justino (Org.). Fazer e ensinar história da educação. Braga: Instituto de Educação e Psicologia, 1998. p. $147-154$.

\footnotetext{
Frigerio e Poggi (1996) nos falam do estrangeiro como requisito metodológico na análise da instituição educativa, considerando o estrangeiro tanto um lugar, como uma pessoa ou um território do conhecimento. As autoras discutem que quem estuda a instituição escolar pode fazer um esforço de se colocar como estrangeira à própria instituição, ou estrangeiro aos saberes e conhecimentos veiculados nela, de forma a revisitá-los, problematizá-los. O estrangeiro traz a contribuição de um diferente, um olhar do outro.
} 
FERNÁNDEZ, Lídia M. Crise e dramática da mudança: avanços de pesquisa sobre projetos de inovação educativa. In: BUTELMANN, I da. Pensando instituições. Porto Alegre: Artmed, 1998. p. 157-203.

FRIGERIO, Gracierla; POGGI, Margarita. El analisis de la instituición educativa: Hilos para tejer proyectos. Buenos Aires: Santillana, 1996.

GATTI JUNIOR, Décio. A história das instituições educacionais: inovações paradigmáticas e temáticas. In: ARAÚJO, José Carlos Souza; GATTI JUNIOR, Décio (Org.). Novos temas em historia da educação brasileira: instituições escolares e educação na imprensa. Campinas: Autores Associados; Uberlândia/ MG: EDUFU, 2002. p. 3-24.

KOCH, Ingedore Grunfeld Vilhaça; TRAVAGLIA, Luiz Carlos. Texto e coerência. São Paulo: Cortez, 2000.

MAGALHÃES, Justino. Contributos para a história das instituições educativas entre a memória e o arquivo. In: FERNANDES, Rogério; MAGALHÃES, Justino (Org.). Para a história do ensino liceal em Portugal. Braga: Universidade do Minho, 1999. p. 63-78.

NUNES, Clarice. História da educação Brasileira: novas abordagens de velhos objetos. Teoria \& Educação, Porto Alegre, n. 6, p. 151-182, 1992. 